\title{
Neonatal hyperbilirubinaemia and its early outcome
}

\author{
D. Nepal, ${ }^{1}$ D. Banstola, ${ }^{2}$ A. K. Dhakal, ${ }^{3}$ U. Mishra, ${ }^{4}$ C. Mahaseth. ${ }^{4}$ \\ ${ }^{1}$ Kanti Children Hospital Kathmandu; ${ }^{2}$ Department of Physiology Tribhuwan University Teaching Hospital; ${ }^{3}$ Department \\ of Paediatrics Tribhuwan University Teaching Hospital; ${ }^{4}$ National Academy of Medical Science, Kathmandu, Nepal.
}

Correspondance to: Deepeshwara Nepal, Kanti Children Hospital Kathmandu

Email:dnepal123@hotmail.com

\begin{abstract}
Introduction: Jaundice is an important cause of morbidity in the neonatal period, especially in the 1 st week of life. our Objective of the study was to find out early outcome of babies admitted in Kanti Children Hospital with neonatal jaundice (NNJ) and its association with other co-morbidities.
\end{abstract}

Methods: This is a retrospective study conducted in tertiary care paediatric hospital from 1st March to1st June 2009. Altogether 73 babies were included in the study. Results: Male babies outnumbered females $(72.6 \%$ vs. $27.4 \%)$. Only $2.4 \%$ babies were near-term. Low birth weight (LBW) babies constituted $19.2 \%$ of the study population. Clinical sepsis as defined by WHO criteria was observed in $86.3 \%$ of babies. Nearly $50 \%$ of the babies had serum bilirubin of $15-19.9 \mathrm{mg} / \mathrm{dl}$. Most of the babies (94.5\%) improved with $5.5 \%$ of mortality.

Conclusions: hyperbilirubinaemia is one of the most common causes of hospital admission in our nursery and it is associated with various other clinical morbidities. Phototherapy is effective in most of the time, but exchange transfusion should also be carried out when phototherapy fails. Causes of hyperbilirubinaemia should be searched extensively especially to rule out haemolysis

Key words: Hyperbilirubinaemia, kernicterus, neonates, phototherapy

\section{Introduction}

Jaundice is an important cause of morbidity in the newborn period, especially in the first week of life. It is a cause of concern for the physician and a source of anxiety for the parents. Jaundice in the newborn is a unique problem because most of the time it is unconjugated hyperbilirubinaemia which when elevated at pathological range is potentially toxic to the developing brain of the infant and may lead to kernicterus. Most jaundice is benign, but because of potential toxicity of bilirubin, newborn infants must be monitored to identify those who might develop severe hyperbilirubinaemia and in rare cases, 'acute bilirubin encephalopathy' or kernicterus. ${ }^{1}$

Nearly, $60 \%$ of the neonates of full term delivery become visibly jaundiced in the 1 st week of life. ${ }^{2}$ The risk of developing jaundice is more in preterm infants. A study in Indian reported $5.7 \%$ neonates requiring phototherapy for jaundice. ${ }^{3}$ of the infants defined as hyperbilirubinaemia, the maximum level of serum total bilirubin (STB) exceeded 20 $\mathrm{mg} / \mathrm{dl}$ in $2 \%$ representing $0.25 \%$ of all the birth. ${ }^{2}$ Approximately 2-4\% of exclusively breastfed term babies have jaundice in excess of $10 \mathrm{mg} / \mathrm{dl}$ in the $1 \mathrm{st}$ week of life. ${ }^{4}$ Hyperbilirubinaemia in newborn is defined as the need for phototherapy according to the American Academy of Paediatrics (AAP) guidelines. ${ }^{5}$ Traditionally, a distinction has been made between benign physiologic jaundice and hyperbilirubinaemia which is either pathologic in origin or severe enough to be considered for further evaluation and intervention. STB concentration have been defined as nonphysiologic in term newborn if the concentration exceed $5 \mathrm{mg} / \mathrm{dl}(86 \mathrm{~mol} / \mathrm{L})$ on the $1 \mathrm{st}$ day of life, $10 \mathrm{mg} / \mathrm{dl}(171 \mathrm{~mol} /$ $\mathrm{L})$ in 2nd day, or $12-13 \mathrm{mg} / \mathrm{dl}(205-222 \mathrm{~mol} / \mathrm{L}) .{ }^{6}$ Thereafter STB elevation exceeding $17 \mathrm{mg} / \mathrm{dl}$ ( $291 \mathrm{~mol} / \mathrm{L}$ ) should be presumed pathologic warranting investigation for a cause and possible therapeutic intervention such as pototherapy. ${ }^{7}$

A clinical practice guideline for phototherapy from AAP applies to the newborn infants of 35 or more weeks of 
gestation. Newborn infants of 35 weeks or more are at increased risk of hyperbilirubinaemia as they are considered near term and are discharged from the hospital within 24 hours of birth. Newborns at 35-36 weeks of gestation are 13 times more likely than 40 weeks gestation to be readmitted for severe jaundice.

Low concentration of bilirubin may have some antioxidant benefits; hence it should not be completely eliminated. ${ }^{8}$ The risk of developing Kernicterus has been seen in neonates with serum bilirubin of $20-25 \mathrm{mg} / \mathrm{dl}$ (340-408 mol/ L). ${ }^{9}$ As haemolytic disease of the newborn has been particularly associated with kernicterus, identification of overproduction of bilirubin is useful in the early detection of bilirubin toxicity. ${ }^{2}$

Kanti Children Hospital is the only tertiary care hospital in the country with neonatal intensive care facility and $\mathrm{NNJ}$ is one of the common conditions for admission and treatment. There has been no recent study of NNJ at this hospital and it was considered to be worthwhile doing this study.

\section{Methods}

This was a retrospective study conducted at Kanti Children Hospital a tertiary care paediatric hospital. The objective was to find out the early outcomes of newborn babies admitted with Jaundice and to identify co morbid conditions associated with neonatal jaundice.

All newborn infants 35 weeks and above admitted to Kanti Children Hospital with the diagnosis of NNJ (STB level >15 $\mathrm{mg} / \mathrm{dl}$ ) were included in the study .Those babies who were admitted to Kanti Children Hospital from 1st March to 1st June 2009 were selected and studied. Clinical sepsis was defined as WHO criteria, septic screen positive babies were those who had two positive parameters on septic screen, meningitis was leveled when CSF report showed and 30cells/ HPF and birth asphyxia was leveled when APGAR score was less than six at five minutes of birth.

Serum bilirubin $>15 \mathrm{mg} / \mathrm{dl}$ was taken significant as this is a routine practice in our hospital to admit and investigate all newborn with serum bilirubin $>15 \mathrm{mg} / \mathrm{dl}$.

All the neonates having significant hyperbilirubinaemia were treated with phototherapy. Early outcomes were studied in the form of complete recovery, recovered with neurological impairments and death. Data were analyzed by SPSS-10th version.

\section{Results}

All together 361 neonates were admitted in Kanti Children Hospital during the study period. Among them 73 babies fulfilled the study criteria for enrolment which constitutes $20 \%$ of neonatal morbidity. Male babies $(72.6 \%)$ outnumbered female babies. Forty (54.8\%) babies were born to primi-para mother and only $6(8.2 \%)$ babies were nearterm. LBW babies constituted $14(19.2 \%)$ and only 17 $(23.3 \%)$ babies were delivered at home (Table 1).

Table1: Demographic variables of the study population.

\begin{tabular}{|c|c|c|}
\hline $\begin{array}{l}\text { Variables } \\
\text { Percentage }\end{array}$ & & No. \\
\hline 1.Gender & & \\
\hline male & 53 & 72.6 \\
\hline female & 20 & 27.4 \\
\hline 2.Gravida & & \\
\hline primi & 40 & 54.8 \\
\hline multi & 33 & 45.2 \\
\hline 3.Gestation & & \\
\hline agenear-term & 6 & 8.2 \\
\hline term & 67 & 91.8 \\
\hline 4.Birth weight & & \\
\hline LBW & 14 & 19.2 \\
\hline normal & 59 & 80.8 \\
\hline 5.Age at the time of admiss & & \\
\hline - within 24 hours & 3 & 4.1 \\
\hline - 24-72 hours & 20 & 27.4 \\
\hline - 72 hours-7 days & 40 & 54.8 \\
\hline$\bullet>7$ days & 10 & 13.7 \\
\hline 6.Place of delivery & & \\
\hline home & 17 & 23.3 \\
\hline health facilities & 56 & 76.7 \\
\hline 7.Mode of delivery & & \\
\hline - spontaneous vagina & 64 & 87.7 \\
\hline - Caesarean section & 6 & 8.2 \\
\hline - instrumental & 3 & 4.1 \\
\hline
\end{tabular}

As sepsis is the commonest cause of admission in neonatal period in our hospital every baby is screened for sepsis, Lumbar puncture is done in symptomatic sepsis. Clinical sepsis as defined by WHO criteria was found in $86.3 \%$ of babies and among them in $9.6 \%$ it was proven by culture (Fig.1). Almost half of the babies had only moderate hyperbilirubinaemia (15-19.9 mg/dl). Nearly $1 / 3 \mathrm{rd}(32.9 \%)$ babies were $\mathrm{ABO}$ incompatible and $4.1 \%$ babies were $\mathrm{Rh}$ incompatible. Most of the babies' i.e: 69 (94.5\%) improved completely and death was observed in only $4(5.5 \%)$ babies. 


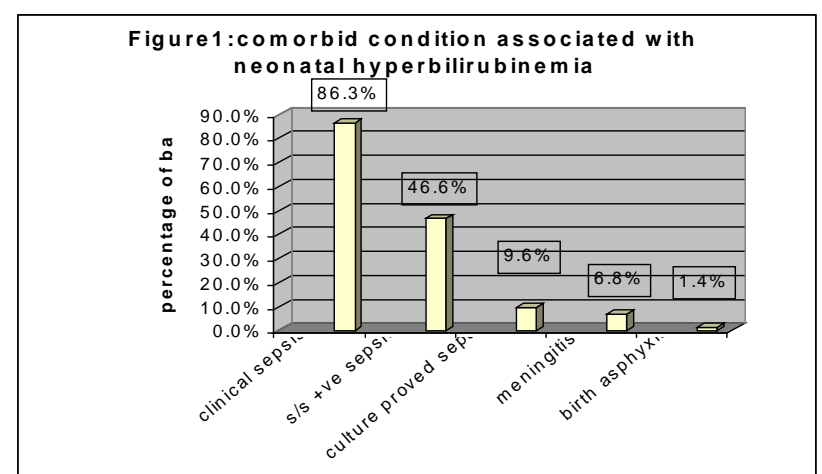

Fig. 1: Comorbidities associated with neonatal hyperbilirubinaemia and sepsis.

More than two third babies had mild hyperbilirubinaemia i.e. their bilirubin level was in the range of $15-19.9 \mathrm{mg} \%$ and only $3 \%$ of babies had maximum rise of STB i.e. $>30 \mathrm{mg} \%$ (Fig 2). At the time of discharge various biosocial characters of hyperbilirubinemic babies such as age, sex, etc were analyzed in terms of early outcomes (Table 2). None of the variables were found to be significantly associated with mortality except birth asphyxia.

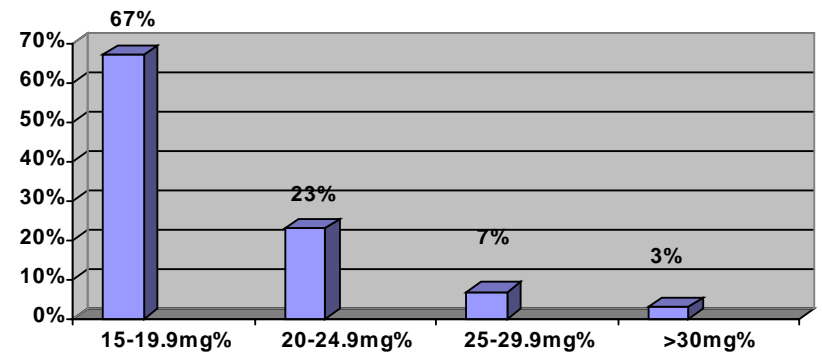

Fig. 2: percentage of babies with maximum level of serum bilirubin.

Table 2: Early outcomes of hyperbilirubinemic babies at the time of discharge along with biosocial characters.

\begin{tabular}{|c|c|c|c|c|}
\hline Variables & $\begin{array}{l}\text { Total } \\
\text { cases }\end{array}$ & $\begin{array}{c}\text { Improved } \\
\text { cases }\end{array}$ & $\begin{array}{l}\text { Death } \\
\text { cases }\end{array}$ & $P$ value \\
\hline $\begin{array}{l}\text { Sex } \\
\begin{array}{l}\text { male } \\
\text { female }\end{array} \\
\end{array}$ & $\begin{array}{l}53(72.6 \%) \\
20(27.6 \%) \\
\end{array}$ & $\begin{array}{l}50 \\
19 \\
\end{array}$ & $\begin{array}{l}3 \\
1 \\
\end{array}$ & 1.0 \\
\hline $\begin{array}{r}\text { Birth weight } \\
\text { LBW } \\
\text { NBW }\end{array}$ & $\begin{array}{l}14(19.2 \%) \\
59(80.8 \%)\end{array}$ & $\begin{array}{l}13 \\
56 \\
\end{array}$ & $\begin{array}{l}1 \\
3 \\
\end{array}$ & 1.0 \\
\hline $\begin{array}{c}\text { Place of delivery } \\
\text { home } \\
\text { health } \\
\text { facilities }\end{array}$ & $\begin{array}{l}17(23.3 \%) \\
56(76.6 \%) \\
\end{array}$ & $\begin{array}{l}16 \\
53\end{array}$ & $\begin{array}{l}1 \\
3 \\
\end{array}$ & 1.0 \\
\hline $\begin{array}{l}\text { Seizure } \\
\text { present } \\
\text { absent }\end{array}$ & $\begin{array}{c}2(2.7 \%) \\
71(97.3 \%)\end{array}$ & $\begin{array}{c}1 \\
68 \\
\end{array}$ & $\begin{array}{l}1 \\
3 \\
\end{array}$ & 0.107 \\
\hline $\begin{array}{r}\text { Birth asphyxia } \\
\text { present } \\
\text { absent }\end{array}$ & $\begin{array}{c}1(1.4 \%) \\
72(98.6 \%)\end{array}$ & $\begin{array}{c}0 \\
69 \\
\end{array}$ & $\begin{array}{l}1 \\
3\end{array}$ & 0.055 \\
\hline $\begin{array}{l}\text { Septic screen }+ \text { ve } \\
\text { sepsis present } \\
\text { absent }\end{array}$ & $\begin{array}{l}34(46.6 \%) \\
39(53.4 \%)\end{array}$ & $\begin{array}{l}32 \\
37\end{array}$ & $\begin{array}{l}2 \\
2 \\
\end{array}$ & 1.0 \\
\hline
\end{tabular}

\section{Discussion}

Hyperbilirubinaemia is one of the most common causes of hospital admission in nurseries. Although jaundice is a benign condition; infants must be monitored to identify those who might develop acute bilirubin encephalopathy or kernicterus. Although Kernicterus should almost always be preventable, cases continue to occur in infants of 35 or more weeks' gestation. The following are the key elements of the recommendation by AAP guideline: ${ }^{4}$

Every clinician should:

1) Promote and support successful breast feeding

2) Perform a systematic assessment before discharge for the risk of severe hyperbilirubinaemia

3) Provide early and focused follow-up based on the risk assessment

4) When indicated, treat newborn with phototherapy or exchange transfusion to prevent the development of severe hyperbilirubinaemia and possible bilirubin encephalopathy.

Infants with 35-37 weeks of gestation were usually treated in well infant nurseries as if they were term infants and managed no differently from those of e" 38 weeks' gestation with respect to diagnosis, treatment and follow-up of hyperbilirubinaemia. ${ }^{10}$ However in another study, infants born at 37 weeks' gestation were much more likely (4 times) to develop a serum bilirubin level of e" $13 \mathrm{mg} / \mathrm{dl}$ than those born to 40 weeks of gestation. ${ }^{11}$ AAP guidelines (subcommittee on hyperbilirubinaemia) recommend that infants at medium risk (e"38 weeks + risk factors or 35-37 6/ 7 weeks and well) and infant at higher risk (35-37 6/7 weeks +risk factors) should be treated at lower bilirubin level as compared to infants at lower risk (e"38 weeks and well) in order to prevent Kernicterus. ${ }^{4}$

There is a strong association between breastfeeding and jaundice in the healthy newborn infants. We have observed that $93.6 \%$ hyperbilirubinaemic babies were on exclusive breastfeeding. This might be due to universal breastfeeding practices in Nepal. Similar finding was observed by Jeffeyet al. He found that of infants for whom no causes for hyperbilirubinaemia was found, $82.7 \%$ were breastfed compared to $46.9 \%$ in control group ( $\mathrm{p}<.0001){ }^{12}$

We observed that maximum number $(67.1 \%)$ of infants' peak serum bilirubin fell in the range of $15-19.9 \mathrm{mg} / \mathrm{dl}$, and the mean serum bilirubin was $400 \mathrm{~mol} / \mathrm{L}$ Similar result was observed by Sgro et al who found that mean peak serum bilirubin was $471 \mathrm{~mol} / \mathrm{L} .{ }^{13}$ In our study, ABO incompability was found in $32.9 \%$ of cases while in another study it was 
$51.6 \% .{ }^{10}$ In our study culture proved sepsis was found in $9.6 \%$ of hyperbilirubinemic babies, where as culture positive was seen in only $1.1 \%$ in Awasthi et al's studies. ${ }^{14}$ However Narang et al mentioned that sepsis contributed $4.49 \%$ cases of hyperbilirubinaemia. ${ }^{15}$ In our study hyperbilirubinaemia was more common in male babies than in female babies (72.6\% vs. $27.4 \%$ ), similar finding were observed by Mantani et al (62\%vs38\%) and Sharma et al (1.3:1). ${ }^{16,17}$ Interestingly we observed that peak serum bilirubin or STB did not have correlation with final outcome which was observed by Mantani et al. ${ }^{16}$ Small sample size and retrospective design are two main drawbacks of this study.

\section{Conclusions}

Hyperbilirubinaemia is one of the most common causes of hospital admission in our nursery and it is associated with various other clinical morbidities. Healthy term babies with a serum bilirubin $<17 \mathrm{mg} / \mathrm{dl}$ should not be admitted routinely as they do not need phototherapy. Phototherapy is effective most of the time, but exchange transfusion should also be carried out when phototherapy fails. Causes of hyperbilirubinaemia should be searched extensively especially to rule out haemolysis (ABO and $\mathrm{RH}$ typing should be routinely done along with Direct Coombs Test, peripheral smear, reticulocyte count and G6PD screening). Detailed neurological examination during admission and at discharge should be recorded.

\section{References}

1. Clinical practice guidelines Management of hyperbilirubinaemia in Newborn infant 35 or more weeks of gestation, pediatrics 2004; 114:297-16.

2. Madan A, MaCMahon JR, DK Stevenson. Neonatal Hyperbilirubinaemia.In HW Taeush, Ballard RA Gleason CA, Eds: Avery's Diseases of the Newborn.Philadelphia: Saunders; 2005:1226-56.

3. National Neonatal Forum of India. National Neonatal Perinatal Database-Report for 2002-2003.New Delhi: NNF India; 2005.

4. Clarkson JE, Cowan JO, and Herbison GP.Jaundice in full term healthy neonates: A population study. Aust Pediatr J 1984; 20:303-8.

5. Maisles MJ,Balter RD,Bhutani V,et.al.Management of hyperbilirubinaemia in the newborn infant 35 or more weeks of gestation.pediatrcs.2004;114:297-316.

6. Hardy JB, Drage JS, Jackson EL.The first year of life. The Collaborative Perinatal Project of the National
Institute of Neurological \& communicative Disorder of stroke.Baltimorre, Johns Hopkins University Press, 1979; p104.

7. Maisels MJ, Gifford K.Normal serum bilirubin level in newborns and effect of breast-feeding .Pediatrics 1986; 78:837-43.

8. Stevenson DK, Fanaroff AA, Maisles MJ, et.al. Prediction of hyperbilirubinaemia in near-term and term Infants.Pediatrics 2000; 108:31-39.

9. Gopinathan V,Millar NJ,Mifner AD, Rice-Evans CA. Bilirubin and ascorbate antioxidant activity in neonatal plasma.FEBS lett 1994;349:197-200.

10. Koch CA,Jones DV,Dine MS et.al.Hyperbilirubinaemia in premature infants: a follow-up study Pediatr. $1959 ; 55: 23-9$

11. Gale R,Seidman DS,Dollberg S,Stevenson DK.epidemiology of neonatal jaundice in the Jerusalem population Pediatr Gastroenterol Nutr.1990;10:82-86.

12. M.Jeffy, Maisles MB, Bachard Kathleen, Giffard RNC. Normal serum bilirubin levels in the newborn and the effect of breast-feeding .Pediatrics 1986; 78:837-43.

13. Michael S, Douglas C and Shah V. Incidence and causes of severe neonatal hyperbilirubinaemia in Canada.CMJA 2006; 175:587-90.

14. Awasthi S and Rehaman H.Early prediction of Neonatal hyperbilirubinaemia. Indian J pediatr 1998; 65:131-39.

15. Narang A, Kumar P, and Kumar R.Neoanatal Jaundice in VLBW babies. Indian J Pediatr 2001; 68:307-9.

16. Mantani M , Patel A, A,Renge R and Kulkarni H.Prognostic value of direct bilirubin in Neonatal Hyperbiliruinemia.Indian J Pediatr 2007;79:819-22.

17. Sharma P, Chhangani N.P, Kesh Ram M, et.al. Brainstem evoked Response Audiometry (BAER) in Neonates with hyperbilirubinaemia. Indian J. Pediatr 2006; 73:413-16. 